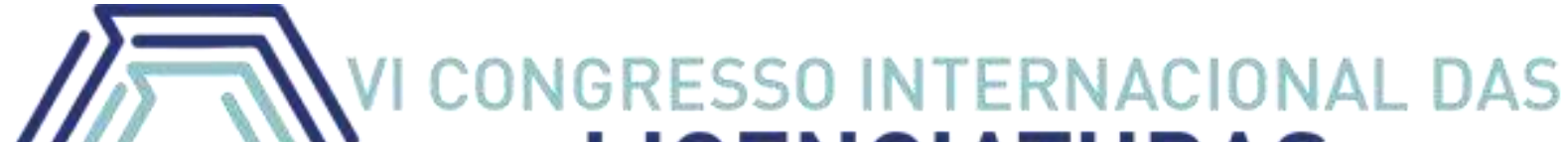 LICENCIATURAS COINTER - PDVL 2019
}

\section{O ENSINO DE CIÊNCIAS ATRAVÉS DE PRÁTICAS CONTEXTUALIZADAS DE EDUCAÇÃO AMBIENTAL}

\author{
LA ENSEÑANZA DE LA CIENCIA A TRAVÉS DE PRÁCTICAS \\ CONTEXTUALIZADAS DE EDUCACIÓN AMBIENTAL
}

\section{THE TEACHING OF SCIENCE THROUGH CONTEXTUALIZED PRACTICES OF ENVIRONMENTAL EDUCATION}

\author{
Apresentação: Comunicação Oral \\ Luana Reine Pinheiro Lima CUNHA ${ }^{1}$; Fausthon Fred da SILVA ${ }^{2}$; Maria Deise das Dores \\ Costa DUARTE ${ }^{3}$.
}

DOI: https://doi.org/10.31692/2358-9728.VICOINTERPDVL.2019.0007

\begin{abstract}
Resumo
A pesquisa propôs inserir a discussão de temas ambientais durante o ensino dos conteúdos da disciplina de Ciências, com enfoque na área de Química, de forma transversal e contextualizada, devido à necessidade da valorização do cotidiano, por ser um dos temas mais discutidos no ambiente do ensino desta matéria, principalmente quanto à relação do aluno com a natureza, sendo ela a chave para o mecanismo de aprendizagem. Este estudo tem um caráter qualiquantitativo; foram utilizados os métodos de abordagem quali-quantitativa, pesquisa em campo e pesquisa colaborativa, elaborado através do Programa Despertar Vocações para as Licenciaturas - PDVL. O projeto foi realizado na Escola Estadual de Ensino Fundamental Professora Ilza de Almeida Ribeiro, com a turma do $9^{\circ}$ ano, turno manhã, que atende aproximadamente 33 alunos, de uma escola pública do município do Conde - PB, sendo dividida em dois momentos: aplicação de um questionário de sondagem para identificar o nível de conhecimento dos alunos sobre os assuntos da área de Química, ligados à temática ambiental; desenvolvimento e aplicação de atividades educativas, como o Jogo do Conhecimento, tomando por base os resultados obtidos nos questionários, e durante a semana do estudante foi desenvolvida uma oficina com duas práticas: produção do desinfetante e o pó para eliminar barata. Ainda foi realizado o Jogo do Dominó e a Palavra Cruzada da Química do Átomo. As atividades desenvolvidas agiram como facilitadores na compreensão dos assuntos de Ciências pelos alunos, uma vez que eles não conseguiam interligar os conteúdos curriculares, com as questões cotidianas e com as práticas ambientais.
\end{abstract}

Palavras-Chave: ensino de ciências, educação ambiental, aula contextualizada.

\footnotetext{
${ }^{1}$ Pós-Graduação em Química, UFPB, luanareine@hotmail.com

2 Departamento de Química, UFPB, fausthon@gmail.com

${ }^{3}$ Mestre, IFPB - Campus João Pessoa, maria.costa@ifbp.edu.com
} 


\title{
Resumen
}

La investigación ha propuesto insertar la discusión de temas ambientales durante la enseñanza de los contenidos de la asignatura de ciencias, con perspectiva en el área de la química, de modo transversal y contextualizada, por causa de la necesidad de la valoración del cotidiano, por ser uno de los temas más discutidos en el ambiente de la enseñanza de esta asignatura, principalmente cuanto la relación del alumno con la naturaleza, siendo ella la llave para el mecanismo de la aprendizaje. Esto estudio tiene un carácter cualitativo y cuantitativo, que fueran aprovechados, los métodos de abordajes cualitativo y cuantitativo, investigación en el campo e investigación colaborativa, elaborado por medio del programa Despertar Vocações para as Licenciaturas - PDVL. Tal proyecto fue realizado en la Escola Estadual de Ensino Fundamental Professora Ilza de Almeida Ribeiro, com la clase del $9^{\circ}$ año, período mañana, que atiende aproximadamente 33 alumnos, de una escuela pública del municipio do Conde - PB, siendo dividida en dos momentos: aplicación de un cuestionario de sondeo para identificar el nivel del conocimiento de los alumnos acerca de temas de química, conectados a la temática ambiental; desarrollo y aplicación de actividades educativas, como juego de conocimiento, con base en los resultados obtenidos de los cuestionarios, y durante la semana de estudiante se desarrolló un taller con dos prácticas: producción del desinfectante y del polvo para eliminar cucaracha. Todavía fue realizado el juego de dominó y la palabra cruzada de química del átomo. Las actividades desarrolladas actuaron como facilitadores en la comprensión de los temas de ciencias por los alumnos, un vez que ellos no lograban interconectar los contenidos del currículo, con las cuestiones diarias y con las prácticas ambientales.

Palabras Clave: ensino de ciências, educación ambiental, aula contextualizada.

\begin{abstract}
The research proposed to insert the discussion of environmental themes during the teaching of contents of the Science discipline, focusing on the area of Chemistry, in a transversal and contextualized way, due to the necessity of the daily valorization, as it is one of the most discussed topics in the teaching environment of this subject, mainly regarding the students' relationship with the nature, being the key to the learning mechanism. This study has a qualitative-quantitative character; were utilized the qualitative-quantitative methods of approaching, field and collaborative research, developed through the Program "Despertar Vocações para a Licenciatura - PDVL". This project was performed at the State Elementary School Professora Ilza de Almeida Ribeiro, with the $9^{\text {th }}$ grade class, morning shift, in which attends approximately 33 students, of a public school in the city of Conde - PB, being divided in two moments: application of a survey questionnaire to identify students' level of knowledge on Chemistry subjects, related to the environmental theme; development and application of educational activities, such as the Knowledge Game, based on the results obtained in the questionnaires, and, during the student week, a workshop was developed with two practices: the production of disinfectant and of a powder to eliminate cockroaches. There was also a Domino Game and the Atom Chemistry Crossword. The activities developed acted as facilitators in the students' comprehension of Science subjects, since they could not interconnect the curriculum contents with daily issues and environmental practices.
\end{abstract}

Keywords: Science teaching, environmental education, contextualized class. 


\section{Introdução}

Os problemas ambientais crescem a cada dia e a escola apresenta uma importante função na discussão de tais questões e na conscientização da comunidade. Embora, atualmente, o acesso à informação esteja disponível é necessário que a escola cumpra o seu papel de mediadora do conhecimento, possibilitando a comunidade escolar uma visão concisa sobre a temática ambiental, pois as vezes falta consciência quanto à influência das ações humanas no ambiente.

Assim, inserir a educação ambiental durante o ensino dos conteúdos das disciplinas curriculares, de forma transversal e contextualizada, é um instrumento valioso para a discussão das questões ambientais e para a formação dos cidadãos conscientes e aptos para vier em uma sociedade sustentável.

Muitas escolas ainda não têm incorporado a educação ambiental como uma prática cotidiana de suas atividades. Como preconiza a Lei $N^{\circ}$ 9.795/1999, que institui a Política Nacional de Educação Ambiental e dá outras providências, "às instituições educativas, devem promover a educação ambiental de maneira integrada aos programas educacionais que desenvolvem" (Lei no 9.795/1999, Art. 3º inciso II).

Na Escola Estadual Professora Ilza de Almeida Ribeiro, que atende ao público escolar da cidade do Conde (PB), representado por comunidades quilombolas, indígenas e rurais, a inserção da educação ambiental nas práticas curriculares não é evidenciada, uma vez que o tema não vem sendo abordado de forma integrada no ensino das disciplinas. Tais comunidades atendidas pela escola, geralmente, apresentam modos de vida diretamente relacionados ao meio ambiente. E, nesse contexto, a falta de debate sobre as questões ambientais e modos de vida mais sustentáveis, através da contextualização do ensino e da educação ambiental, emerge como uma deficiência do papel da escola.

A pesquisa realizada propôs desenvolver atividades de cunho educacional, promovendo o ensino contextualizado da disciplina de Ciências, com enfoque na área da Química e Biologia, e com o auxílio didático de jogos lúdicos, bem como o uso de práticas ambientais.

Em suma, o projeto almejou-se desenvolver ações exitosas com outros pares, ampliando a troca de saberes, conhecimentos e fazeres entre a equipe do projeto e a comunidade escolar, além de capacitar, durante esse processo, professores da rede pública de ensino, da escola parceira do projeto. Já entre os alunos da escola parceira anseia-se desenvolver estratégias de 
conscientização ambiental, sensibilizando-os quanto às questões ambientais, tendo como mediadores os docentes das disciplinas supracitadas, através do uso de mecanismos didáticos como ferramenta.

\section{Fundamentação Teórica}

No contexto educacional, a discussão de tema ambientais, através da educação ambiental, é um importante instrumento de conscientização da sociedade, uma vez que assume um significativo papel como mediadora na transformação do comportamento do homem em relação ao meio ambiente.

Por meio da Lei $N^{\circ} 9.795 / 1999$, a educação ambiental é conceituada como o processo por meio do qual o indivíduo e a coletividade constroem valores sociais, conhecimentos, habilidades, atitudes e competências voltadas para a conservação do meio ambiente.

A referida Lei, instituiu a Política Nacional de Educação Ambiental, a qual é regulamentada pelo Decreto 4.281/2002, que em seu artigo $2^{\circ}$ afirma que "a educação ambiental é um componente essencial e permanente da educação nacional, devendo estar presente, de forma articulada, em todos os níveis e modalidades do processo educativo, em caráter formal e não formal” (BRASIL, 1999).

No artigo $10^{\circ}$, da Lei № 9.795/1999, é destacado que "a educação ambiental será desenvolvida como uma prática educativa integrada, contínua e permanente em todos os níveis e modalidades do ensino formal". Ainda, no parágrafo primeiro do mesmo artigo é destacado que "a educação ambiental não deve ser implantada como disciplina específica no currículo de ensino" (BRASIL, 1999).

Assim sendo, a implantação de atividades de educação ambiental poderá trazer uma agregação de valor aos conteúdos trabalhados nas disciplinas curriculares, bem como contribuirá para tornar o aprendizado significativo, uma vez que abordará temas cotidianos e ligados à vida dos alunos.

Para o desenvolvimento de atividades de educação ambiental é importante que a escola trabalhe de maneira transversal e interdisciplinar, uma vez que, são muitos os conceitos que podem ser abordados através dessa temática.

O trabalho transversal de temas ligados ao Meio Ambiente foi incluído aos Parâmetros Curriculares Nacionais (PCNs), em 1997, o que contribuiu para o desenvolvimento das atividades ligadas à educação ambiental. A partir dos PCNs entendeu-se que, "trabalhar de 
forma transversal significa buscar a transformação dos conceitos, a explicitação de valores e a inclusão de procedimentos, sempre vinculados à realidade cotidiana da sociedade, de modo que obtenha cidadãos mais participantes. Nesse contexto, cada professor, dentro da especificidade de sua área, deve adequar o tratamento dos conteúdos para contemplar o tema Meio Ambiente, assim como os demais temas transversais" (Brasil, 1997).

Assim, a escola emerge como um importante espaço onde cada professor pode integrar os conteúdos específicos de sua respectiva disciplina, ao tema educação ambiental.

É notório que muitos profissionais não dão ênfase a essa temática, dirigindo-se sempre ao ensino especifica de sua área de atuação. Como bem enfatiza Mendonça (2015, p. 63), o ensino formal é baseado em muitas disciplinas, e isso exige que cada professor seja um especialista. Entretanto, paralelamente, muitos esforços vêm sendo feitos para promover o diálogo entre as disciplinas e a conexão entre os temas. Assim, fala-se de multidisciplinaridade, em transdisciplinaridade e em transversalidade.

\begin{abstract}
“(...) pode-se dizer que a multidisciplinaridade envolve várias disciplinas, intervindo no estudo do mesmo objeto, mas sem interações; a interdisciplinaridade, além de justapor, provoca a colaboração entre as disciplinas plurais no estudo de um objeto ou de um campo do saber ou em um objetivo, e há transferência de métodos de uma disciplina para a outra; e a transdisciplinaridade atravessa o conteúdo comum e o que está além das disciplinas, tentando extrair da colaboração entre disciplinas um fio condutor, uma filosofia epistemológica” (Mendonça \& Neiman, 2013, pág. 72).
\end{abstract}

Nesse contexto, Maia (2005) afirma que os professores precisam tornar a aprendizagem dos estudantes significativa, promovendo interações entre os novos conhecimentos e os mesmos já existentes. É necessário que o professor assuma um papel de motivador de seus estudantes, despertando neles o desejo empírico, impulsionando-lhes a pensar e tornarem-se seres críticos e questionadores. E o trabalho com a educação ambiental pode assumir esse papel agregador.

Pegoraro (1995) afirma que:

\footnotetext{
“Quanto mais à escola estiver relacionada com a vida do aluno, mais eficiente ela será. Permitirá que o aluno busque o conhecimento na vivência do cotidiano e nos ambientes aos quais pertença. Se considerarmos que o professor deve ter domínio de conteúdo, este passará aos seus alunos o conhecimento no momento em que se estabeleçam condições de aprendizado, orientando-os na redescoberta do conhecimento, por meio de aplicações de técnicas adequadas".
}

Nesse sentido, a valorização do cotidiano é um dos temas de muitas discussões no ambiente do ensino de Ciências, principalmente quanto à relação do aluno com a natureza. E 
esta relação deve ser a chave para o mecanismo de aprendizagem.

Em relação a introdução da educação ambiental no ensino de Ciências, das disciplinas Química e Biologia, Pegoraro (1995) afirma que a Biologia quando inserida na grade curricular da escola deve visar à compreensão da realidade, buscando a melhoria da qualidade de vida, pois tal disciplina é uma ciência que estuda os seres vivos, a relação entre eles e o meio ambiente, além dos processos e mecanismos que regulam a vida.

Assim, o uso da contextualização do ensino consiste na unificação dos planos de ensino, conectando-os com as temáticas cotidianas, sem deixar de levar em consideração que a aprendizagem dos alunos é um processo interno, por meio de indicadores externos (Delizoicov, et al., 2008). O uso dessa metodologia pode contribuir no planejamento das atividades dos professores, através da criação de novas maneiras de colaborar na formação dos alunos, indicando estratégias que auxiliem na construção de significados reais para a vida cotidiana do alunado.

O desenvolvimento de trabalhos com educação ambiental pode ser realizado dentro do contexto de qualquer disciplina do currículo, onde todas as atividades podem ser trabalhadas fora da sala de aula, em contato com a natureza. Portanto, como destaca Delizoicov et al (2008) a inserção da educação ambiental vai estimular os sentidos, o senso de interesse pelo conhecimento e o entusiasmo de aprender pela experiência.

\section{Metodologia}

A pesquisa tem caráter quali-quantitativo, que foram utilizados, os métodos de abordagens quali-quantitativa, pesquisa em campo e pesquisa colaborativa; técnicas de entrevistas e instrumento de aplicação de questionários.

A Pesquisa Qualitativa de acordo com Gil (1997), trabalha com dados subjetivos, crenças, valores, opiniões, fenômenos, hábitos. A pesquisa quantitativa, segundo Fonseca (2002), trabalha com os resultados que podem ser quantitativos.

Também, o presente estudo foi uma Pesquisa de Campo, que "consiste na observação dos fatos tal como ocorrem espontaneamente, na coleta de dados e no registro de variáveis presumivelmente para posteriores análises" (OLIVEIRA, 2002, p. 6).

Trata-se, também, de um projeto de abordagem escolar que trabalhou a Educação Ambiental de forma unificada nas aulas de Química e Biologia. O projeto foi desenvolvido na Escola Estadual de Ensino Fundamental Professora Ilza de Almeida Ribeiro, com a turma do 
$9^{\circ}$ ano, que atende aproximadamente 33 alunos.

Inicialmente, foram propostas reuniões com o docente responsável pela disciplina de Ciências da turma parceira, a fim de desenvolver uma parceria com o professore e colocar em prática nas aulas as discussões sobre a temática ambiental. Durante essa etapa foi explorado e incentivado um planejamento de ensino, a fim de inserir dentro dos conteúdos da disciplina, práticas ligadas à temática ambiental.

Para tal fim, foi trabalhado pelo professor os conceitos unificadores e seus usos entre na disciplina de Ciências, com enfoque em Química e Biologia, durante as aulas. No que diz respeito ao uso dos conceitos unificadores, Delizoicov et al (2008) diz que, os fenômenos/situações podem ter sua compreensão - e consequente programação e planejamento de ensino - estruturada pelo uso dos conceitos unificadores. Através do uso dos conceitos unificadores, envolvidos nos fenômenos/situações, poderá ser identificada a conceituação cientifica necessária para a sua compreensão.

Com base nos conceitos unificadores foram constituídas uma rede e uma construção pragmática de temas, cujo objetivo é explorar e incentivar um planejamento de ensino e a elaboração de unidades didáticas na perspectiva da abordagem temática. A criação de mapas temáticos, a partir dos conceitos unificadores, será estimulada entre os professores, bem como sua utilização em sala de aula. Também, foram aplicados questionários de sondagem contendo oito questões, cinco fechadas e três abertas, com os alunos da turma selecionada, envolvendo conhecimentos das áreas de Química e Biologia, e sua ligação com os temas ambientais. Através desses questionários pode-se determinar o nível de conhecimento dos discentes sobre os assuntos abordados, proporcionando um enfoque diferenciado na contextualização das aulas.

Assim, os resultados obtidos a partir dos questionários, auxiliaram na elaboração dos planos de aulas, bem como nas atividades complementares de caráter educacional, voltadas para o uso da educação ambiental nas aulas de Ciências, tais como aulas contextualizadas, jogos lúdicos e oficinas.

Essas ferramentas de ensino contribuíram para uma prática de ensino inovadora e dinâmica, tornando o aprendizado mais divertido e relevante. Nesse sentido, apesar dessas ferramentas auxiliarem no processo ensino-aprendizagem, estas atuam como facilitadores para a compreensão positiva dos conteúdos de Química e Biologia, pelos alunos.

Partindo do pressuposto, que as matérias de Ciências podem ser trabalhadas fora do contexto da aula tradicional, através de aulas mais dinâmicas e sempre envolvendo assuntos do 
cotidiano, e pôr a escola em questão está inserida em uma área rural, utilizar-se-á o próprio ambiente como uma exemplificação da temática abordada. Pois, como bem destaca Delizoicov et al (2008), a natureza irá estimular os sentidos, o senso de interesse pelo conhecimento e o entusiasmo de aprender pela experiência. Assim, durante as aulas de química e biologia, alunos com dificuldades em temas específicos podem superá-las sendo levados a um local aberto, em contato mais próximo com a natureza e seu dia-a-dia.

\section{Resultados e Discussão}

Partindo das informações obtidas na aplicação do questionário, como mostra o Gráfico 1, pode-se constatar a carência do ensino contextualizado na temática ambiental para as disciplinas curriculares da Escola Estadual Professora Ilza de Almeida Ribeiro. Isso surge como uma deficiência do papel da escola, tendo em vista que a escola parceira atende um público representado por comunidades quilombolas, indígenas e rurais, os quais apresentam um modo de vida diretamente relacionada com o meio ambiente. Nesse contexto, é de fundamental importância a escola promover debates durante as aulas sobre as questões ambientais, enfocando a educação ambiental e a temática da sustentabilidade

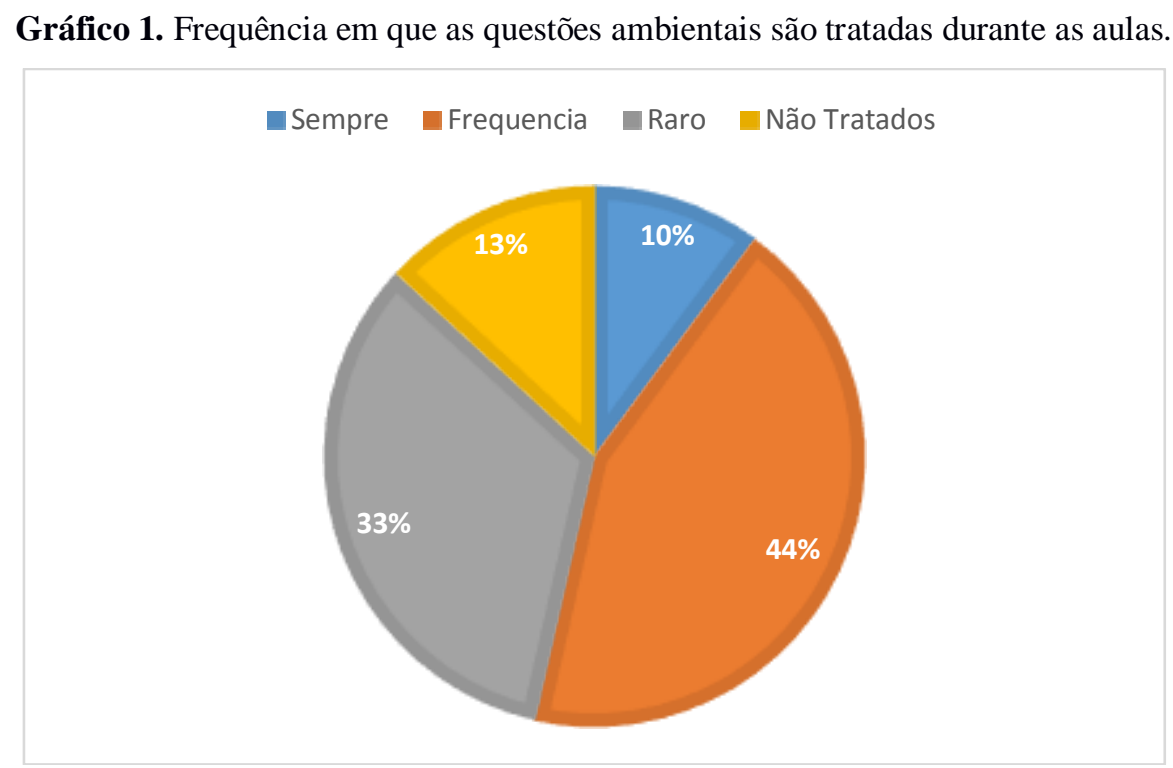

Fonte: Própria (2016)

Dentre as atividades ambientais propostas pelos alunos para serem desenvolvidas na escola, foi destacada como mostra o Gráfico 2, principalmente, a atividade de reciclagem. E, observa-se ainda, que $37 \%$ dos alunos não souberam propor atividades com enfoque no tema 
ambiental pela carência do ensino contextualizado nessa temática.

Gráfico 2. Atividades voltadas ao tema ambiental para serem desenvolvidas.

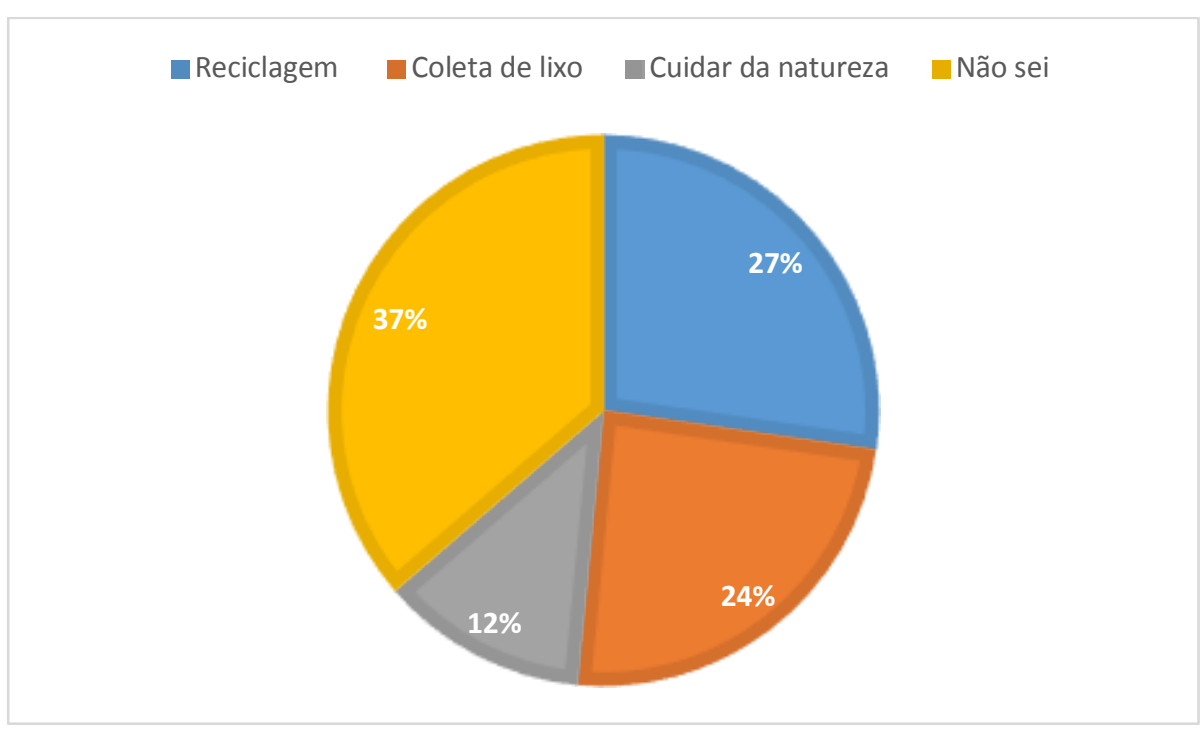

Fonte: Própria (2016)

Como os alunos destacaram a necessidade de uma atividade de reciclagem, foi elaborado um jogo do conhecimento (Figura 1), onde foram trabalhados dos elementos químicos, associando esse conteúdo ao tempo de decomposição de alguns resíduos sólidos encontrados cotidianamente, bem como foi trabalhada a prática dos 3R's (Reduzir, Reutilizar e Reciclar).

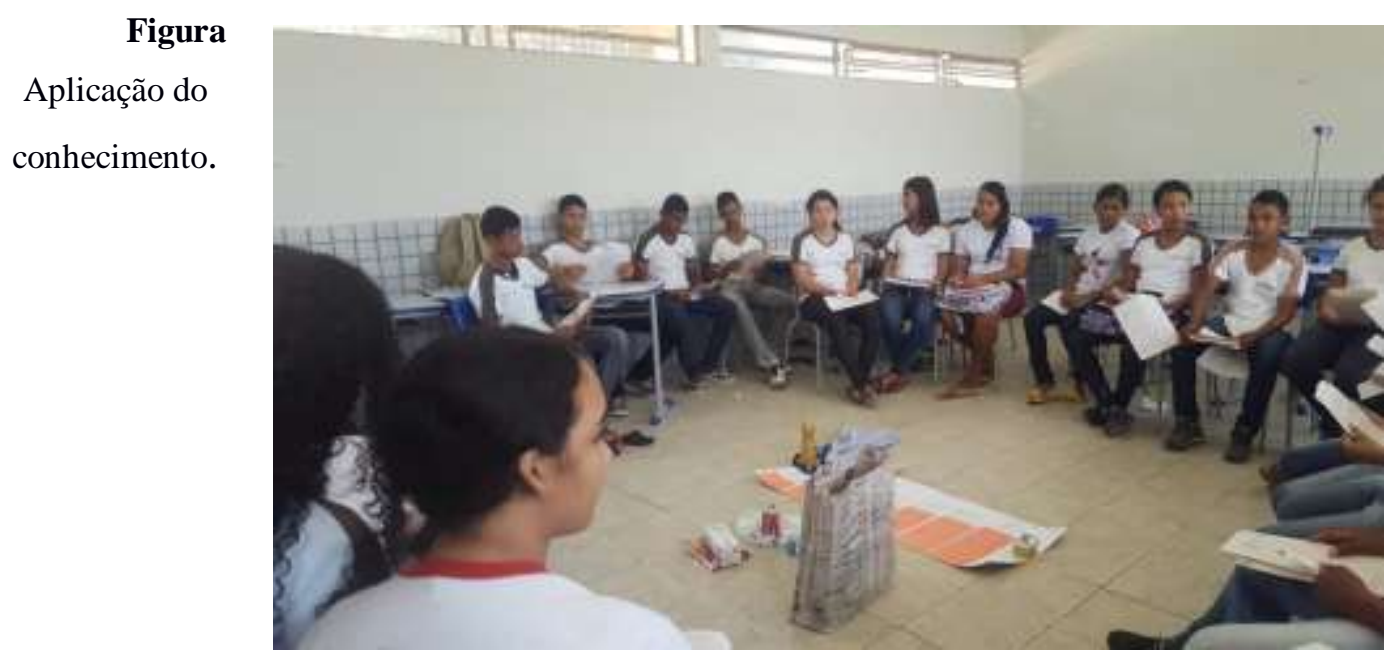

1.

jogo do 
Foi desenvolvido ainda, o jogo de memória fazendo uma abordagem aos elementos químicos ligados ao cotidiano, sendo previamente

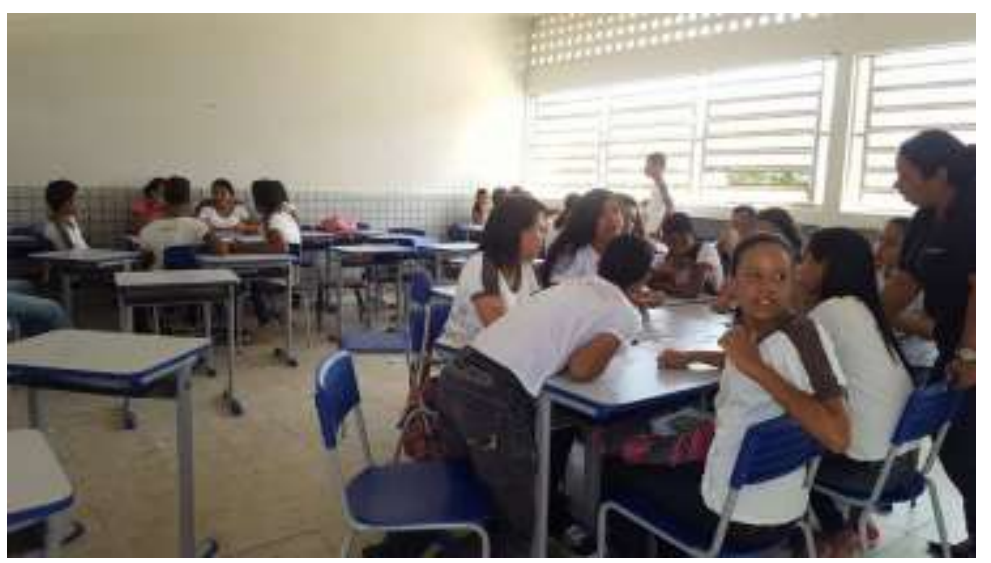

contextualizados com as questões de educação ambiental, utilizando um cartaz para o apoio teórico (Figura 2).

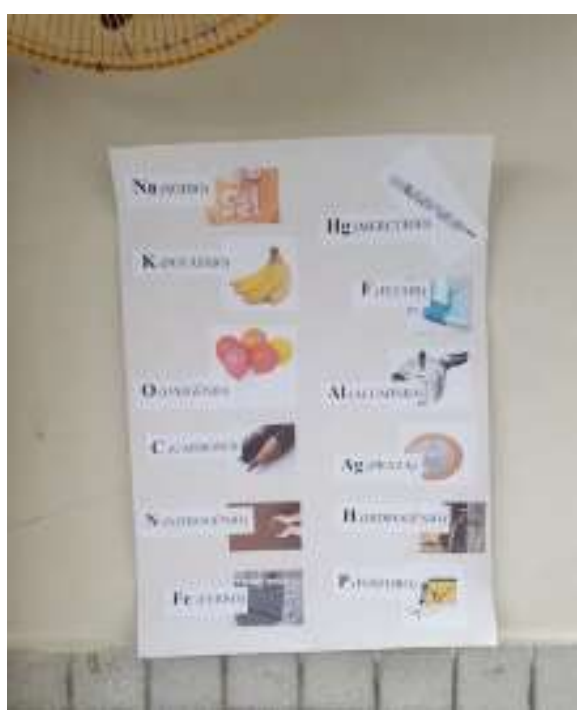

Figura 2. Aplicação do jogo da memória e o cartaz de apoio.

\section{Fonte: Própria (2016)}

E, ainda, foi desenvolvido o jogo da palavra cruzada da Química do átomo (Figura 3). Tendo como finalidade auxiliar os alunos na aprendizagem do conteúdo de Modelos Atômicos, através de deste jogo lúdico.

Figura 3. Jogo da palavra cruzada da Química do átomo. 


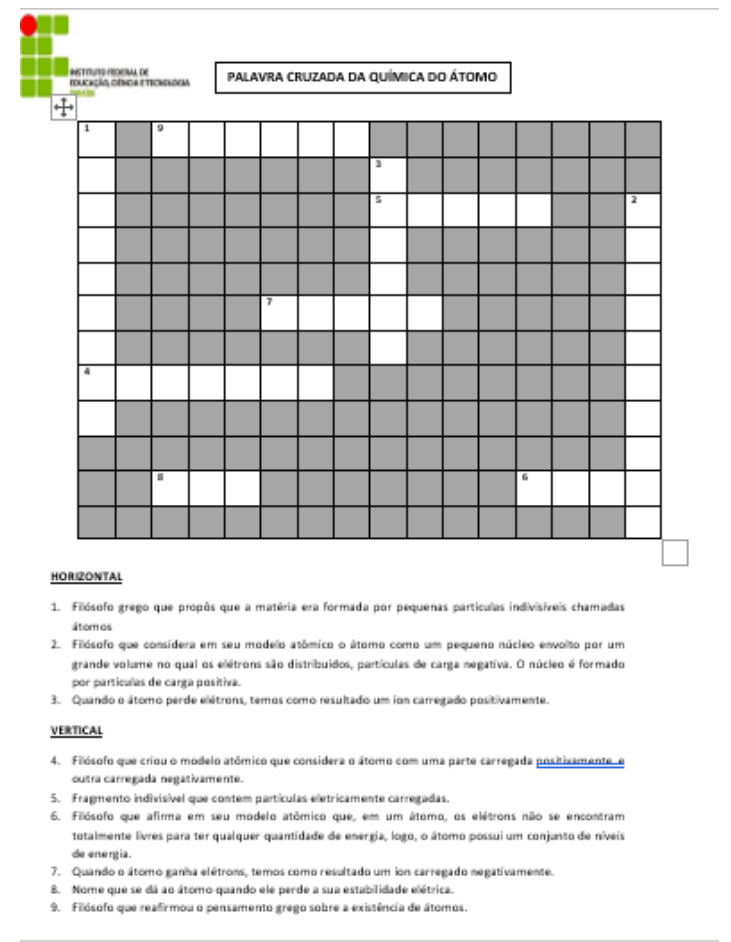

Fonte: Própria (2016)

No entanto, a execução desses tipos de atividades nem sempre é algo fácil para os docentes, devido à dificuldade de aplicar um ensino transversal e contextualizados que forneça uma vivencia não só baseada na dinâmica tradicional da sala de aula, mas também nas vivencias cotidianas dos discentes.

Segundo Gonçalves (2012), muitos educadores apresentam dificuldades ou, até mesmo, certa resistência quanto à inserção da Educação Ambiental em suas práticas educacionais, em suas atividades rotineiras.

Na semana do dia do estudante, realizada pela escola, foram desenvolvidas duas práticas através de uma oficina da disciplina de Ciências, utilizando material de fácil acesso e de baixo custo, monetário e para o meio ambiente, como mostra a Figura 4, foram realizadas as oficinas de produção de desinfetante (Figura 4) e de inseticida (pó de eliminar barata), com os alunos.

Figura 4. Material utilizado nas oficinas. 


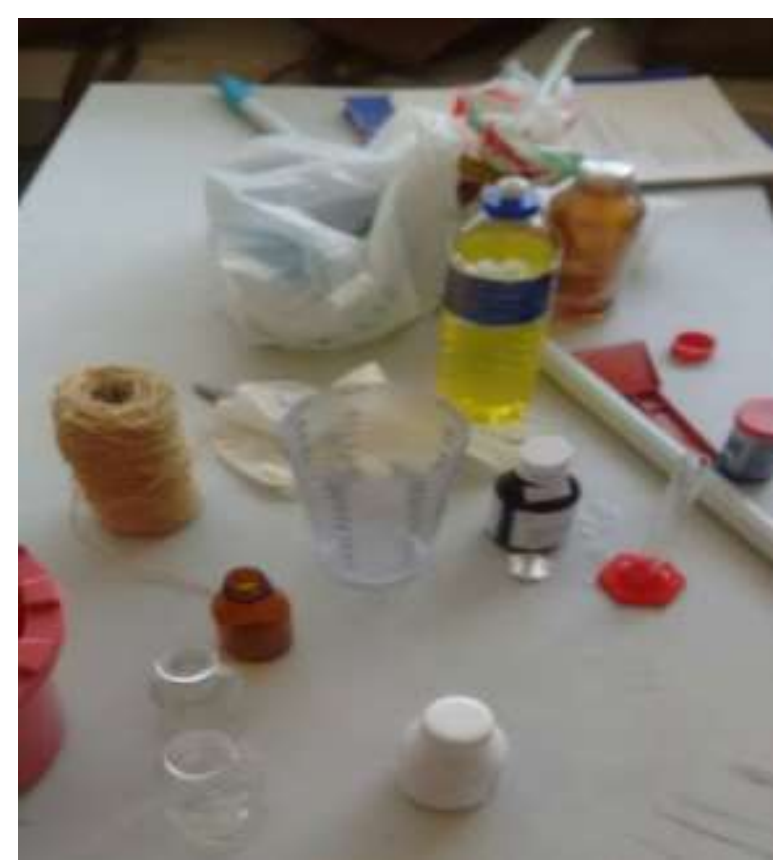

Fonte: Própria (2016)

$\mathrm{Na}$ execução da oficina de produção de desinfetante (Figura 5) foi demonstrada e realizada a mistura de algumas substâncias químicas, como: essência, detergente neutro, brancol, bactericida e água. Bem como, na oficina de produção da substância para eliminar inseto utilizou-se os seguintes reagentes: Ácido Bórico, Farinha de Trigo, açúcar e anilina comestível.

Figura 5. Oficina de preparação do desinfetante.

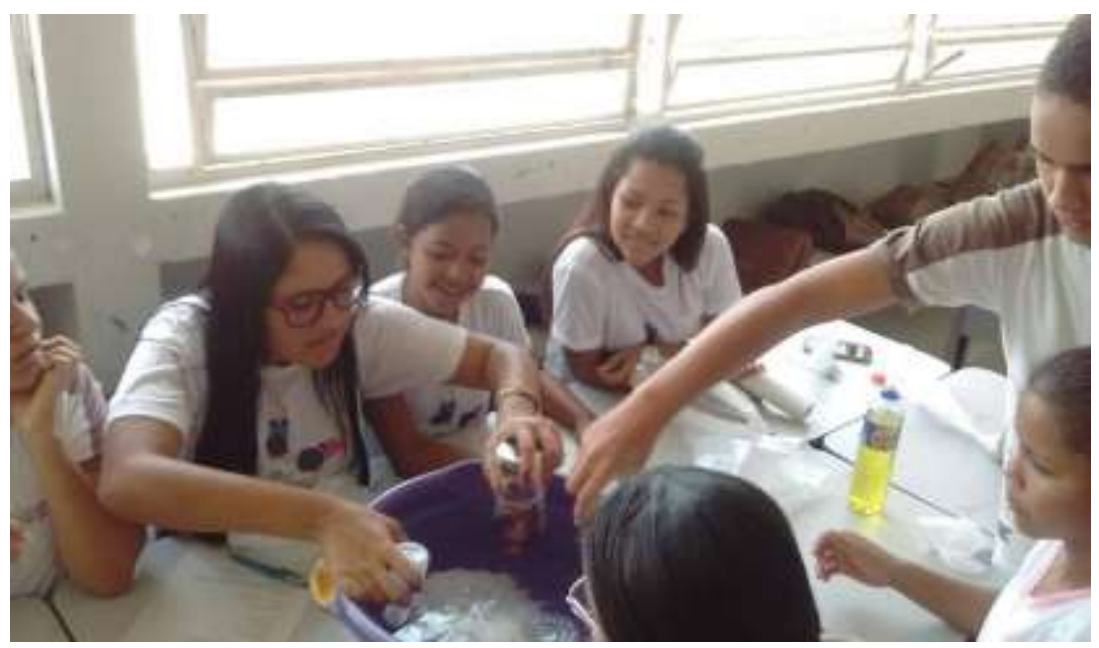

Fonte: Própria (2016) 
A finalidade da prática era demonstrar para os alunos a questão de misturas simples, utilizando os produtos que estão no nosso dia-a-dia, os quais têm uma importância social, econômica e ambiental. Ou seja, ao invés de gastar comprando desinfetante ou pó para eliminar barata, podem produzir estes produtos, utilizando os materiais que tem na própria casa e alguns que são comprados são de fácil acesso.

No geral, os resultados obtidos a partir do questionário de sondagem, mostraram que a escola parceira do projeto não utiliza com frequência aulas contextualizadas com as questões ambientais. Com isso, os alunos apresentam dificuldades em associar os problemas do meio ambiente, vivenciados em suas comunidades com os conteúdos ministrados em sala de aula.

Assim, a aplicação de atividades utilizando o ensino contextualizado na disciplina de Ciência, em especial de Química e Biologia, com o suporte da educação ambiental, podem auxiliar na aprendizagem dos alunos, onde eles conseguirão interligar os conteúdos curriculares, com as questões cotidianas e com as práticas ambientais.

\section{Conclusões}

Os resultados obtidos a partir do questionário de sondagem mostraram que a escola parceira não utiliza com frequência aulas contextualizadas vinculadas as questões ambientais. Por este motivo, os alunos apresentam dificuldades em relacionar os problemas do meio ambiente, vivenciados em suas comunidades com os conteúdos ministrados em sala de aula.

Desde modo, a aplicação das atividades utilizando o ensino contextualizado na disciplina de Ciências, em especial de Química, proporcionaram um suporte na aprendizagem dos alunos, onde eles não conseguiam interligar os conteúdos curriculares, com as questões cotidianas e com a temática ambiental.

De maneira geral, as atividades desenvolvidas no estudo contribuíram para uma prática de ensino inovadora e dinâmica, tornando o aprendizado mais divertido e relevante. Nesse sentido, apesar dessas ferramentas de ensino auxiliarem no processo ensino-aprendizagem, atuaram como facilitadores para a compreensão positiva dos conteúdos de Química, pelos alunos.

\section{Referências}

ABÍLIO, F. J. P.; SATO, M. Métodos Qualitativos e Técnicas de Coleta de Dados em Pesquisas com Educação Ambiental. In: ABÍLIO, F. J. P.; SATO, M. Educação Ambiental: do currículo da Educação Básica às experiências educativas no contexto do Semiárido Paraibano. João 
Pessoa, PB: Editora Universitária da UFPB, p. 19-76. 2012.

AULER, D. Enfoque ciência-tecnologia-sociedade: pressupostos para o contexto brasileiro. Ciência \& ensino. 2007 v.1, número especial, p. 20, nov.

BRASIL. LEI No 9.795, DE 27 DE ABRIL DE 1999. PNRS - Política Nacional de Educação Ambiental. Disponível em:<http://www.planalto.gov.br/ccivil_03/Leis/19795.htm>. Acesso em: 22 out. 2015.

BRASIL. Parâmetros Curriculares Nacionais: introdução aos parâmetros curriculares nacionais. Brasília: MEC/SEF, 1997

DELIZOICOV. D.; ANGOTTI, J.A.; PERNAMBUCO, M.M ${ }^{\mathrm{a}}$. Ensino de Ciências: fundamentos e métodos. São Paulo: Cortez, 2008.

FONSECA, J. J. S. Metodologia da pesquisa científica. Fortaleza: UEC, 2002.

GIL. Metodologia da Pesquisa. Rio de Janeiro: PUC, 1997.

JERÔNIMO, M. A. M. Dificuldades dos alunos da EJA para interpretar e resolver situações-problema matemáticos. 2007. 99 f. Monografia (Curso de Especialização em Educação Profissional Técnica de Nível Médio na modalidade de Jovens e Adultos) Universidade Federal da Paraíba, Bananeiras, 2007.

JACOBI, P.R.; TRISTÃO, M.; FRANCO, M.I.G.C. A função social da educação ambiental nas práticas colaborativas: participação e engajamento. Cad. Cedes, Campinas. 2009. vol. 29. n. 77. p. 63-79, jan./abr.

MAIA. P. Instituto nacional de ciência e tecnologia de transferência de materiais. Fortaleza, Ceará- Brasil, 2005.

MENDONÇA, RITA. Atividades em áreas naturais. São Paulo: Instituto Ecofuturo, 2015. MENDONÇA, RITA E ZYSMAN, NEIMAN. A Natureza como educadora transdisciplinaridade e educação ambiental em atividades extra-classe. São Paulo: Editora Aquariana, 2013.

OLIVEIRA, S. L. Tratado de metodologia científica: projetos de pesquisas: TGI, TCC, monografias, dissertações e teses. São Paulo: Pioneira Thomson Learning, 2002.

PEGORARO, O.M.E. Grau de Interesse dos Alunos Diante do Trabalho Realizado Pelos Professores de Biologia: Em busca de uma explicação. Semina: Ci. Soc./Hum. Ed. Especial. 1995. v. 16., n. 2. p. 43-48. 